\title{
Ôrí e as vozes e o olhar da diáspora: cartografia de emoções políticas*
}

\author{
Gilberto Alexandre Sobrinho**
}

\section{Resumo}

Análise do documentário Ôrí (direção Raquel Gerber, 1989). Elaborado durante 11 anos, entre 1977 e 1988, o filme assume o ponto de vista de uma intelectual e militante negra, Beatriz Nascimento, uma presença inaugural no âmbito do documentário brasileiro, que narra a partir de suas ideias e entrelaça os acontecimentos relacionados aos movimentos sociais dos negros no Brasil. O estudo contextualiza a realização do filme e o aborda por dois vieses: primeiro, por meio dos efeitos de sentido da voz de Beatriz Nascimento e sua performance conceitual, centrada nas ideias de transmigração e quilombo; segundo, pela noção de montagem cartográfica, que comprime a longa duração da experiência da realização do filme e imprime um forte sentimento de lugar, sendo esse lugar os espaços atravessados pelo ser e estar negro no mundo.

Palavras-chave: Filme Ôrí- documentário, Raquel Gerber, Beatriz Nascimento, Mulher Negra.

* Recebido em 20 de dezembro de 2019, aceito em 10 de março de 2020.

** Professor do Departamento de Multimeios, Cinema e Comunicação, Instituto de Artes, UNICAMP, Campinas, SP, Brasil. gilsobri@unicamp.br / ORCID: 00000002-5083-384X 
Ôri and The Voices and The Look of The Diaspora: Cartography of Political Emotions

\begin{abstract}
:
Analysis of the documentary Ôri (Raquel Gerber, 1989). Developed over 11 years, between 1977 and 1988, the film takes the point of view of the black intellectual and militant Beatriz Nascimento, an inaugural presence within the scope of Brazilian documentary, which narrates from her ideas and intertwines these with events related to the black social movements in Brazil. The study contextualizes the making of the film and approaches it from two directions: through the meanings of Beatriz Nascimento's voice and her conceptual performance, centred on the ideas of transmigration and quilombo; and from the notion of cartographic montage, which compresses the long duration of the experience of making the film and gives a strong feeling of the relationship between the notion of place and blackness.
\end{abstract}

Keywords: Documentary Ôrí, Documentar, Raquel Gerber, Beatriz Nascimento, Black Woman. 
O narrador é a figura na qual o justo se encontra consigo mesmo.

Walter Benjamin

Na religião do "Candomblé" os movimentos exprimem conexões com forças naturais como a água, o fogo, a terra, o vento. É, portanto, uma união da essência, da energia e do espírito, três grandes suportes da vida. Se nisso

há um mistério, é preciso tocá-lo, desvelá-lo, e conhecer os efeitos da comunicação do Universo com o homem. Raquel Gerber

É preciso a imagem para recuperar a identidade. Tem-se que tornar-se visível, porque o rosto de um é o reflexo do outro, o corpo de um é o reflexo do outro e em cada um o reflexo de todos os corpos. A invisibilidade está na raiz da perda da identidade; então, eu conto a minha experiência, e não ver Zumbi, que para mim era o herói. Beatriz Nascimento

Ôrí é um filme sobre o processo de libertação do povo negro brasileiro e os modos pelos quais os afrodescendentes têm organizado os seus territórios, desde o próprio corpo até a ocupação do espaço, sendo a diáspora a conexão entre continentes e modos de vida. Essa articulação coloca-se como um gesto assertivo para repensar o Brasil, principalmente sobre conceitos dominantes. Com isso, o filme propõe mudanças radicais, que passam pelos processos de revisão, do ponto de vista da formação nacional, reivindicando-se $e$ atualizando um posicionamento afrocentrado, uma outra narrativa da nação. Esse processo é desencadeado, no filme, por uma mulher negra, uma 
presença que atesta, enfaticamente, uma ausência histórica no domínio do documentário nacional, até então. Portanto, há uma postura singular, já que essa voz domina no filme e articula seu pensamento, tensionando entre o individual e o coletivo, e, consequentemente, estabelece outros parâmetros para 0 pensamento identitário da nação, à medida que gênero, raça $e$ classe, articulados com a potência da memória e do passado, se entrecruzam nesse processo de reflexão.

Beatriz Nascimento, narradora e roteirista do filme dirigido por Raquel Gerber, conduz uma saga, sendo ela, historiadora e protagonista de um deslocamento radical em relação a uma visão discursiva opressiva que estabelecia a senzala como tropo privilegiado para a historiografia alocar o negro, para destacar o quilombo, momento de ressignificar sua importância e reiterar a sua continuidade para compreensão das dinâmicas sociais, políticas, econômicas e culturais afro-centradas, sendo a figura de Zumbi, o herói civilizador e guia para contar essa outra história do Brasil.

O processo de realização do filme Ôrí começou no final dos anos 1970, momento em que a politização dos debates alcançava amplamente a sociedade brasileira e o filme promoveu, em sua gênese, a convergência entre e insurgência de movimentos sociais pela afirmação dos direitos plenos da população negra e os embates da descolonização cultural ${ }^{1}$ que tocavam o cinema, sendo o documentário Ôrí uma das peças contundentes dessas disputas.

\footnotetext{
${ }^{1}$ Ao longo dos 1960 e 1970, no Brasil, o interesse em diretores e diretoras em relação aos temas afro-brasileiros em filmes de ficção e documentário ampliou-se gradativamente, sendo a última década testemunha de um interesse muito maior, sobretudo diante das possibilidades de produção no âmbito do curta-metragem e do apoio estatal (Embrafilme). Diretores tais como Linduarte Noronha, Glauber Rocha, Cacá Diegues, Paulo Cesar Saraceni, Walter Lima Júnior, para citar alguns inseridos no movimento do Cinema Novo colocaram no centro das narrativas, o negro. Na década seguinte, Geraldo Sarno, Zózimo Bulbul, Antonio Pitanga, Valdir Onofre, Odilon Lopez e Juana Elbein dos Santos incrementaram essas representações, além de atestarem a emergência de diretores negros $e$ diretoras mulheres.
} 
Beatriz Nascimento é um nome que desponta nessa arena, tanto para o movimento social, quanto para as querelas culturais. Assim, com a publicação de seu texto "A Senzala vista da Casa Grande", sobre o longa-metragem Xica da Silva (1976), de Cacá Diegues, a autora não economiza em realçar os modos pelos quais o filme reitera estereótipos de inferiorização dos negros ${ }^{2}$. E a partir dessa inserção, ela retoma o debate no campo cinematográfico, posteriormente, com a comunicação intitulada "A Senzala vista da Casa Grande: Merchandise e a Contracultura no Cinema Nacional" $(1981)^{3}$, onde desenvolve ideias que seriam incorporadas no texto "Cinema e descolonização" (Xavier, 1982) ${ }^{4}$. Assim, anos depois dos debates sobre o filme, ela faz a seguinte síntese, em que pesa o argumento de assincronia do longametragem:

Veja bem, que Xica da Silva surge no momento em que toda uma faixa etária de jovens negros se ocupam em protestar contra a discriminação racial através do som e da dança do Black Soul nas grandes cidades do Brasil. Sua

2 "Vejamos porque Xica da Silva é um equívoco. O diretor foge propositadamente à fidelidade histórica em relação ao episódio. Talvez seja uma justificativa afirmar que uma obra artística para se concretizar não pressupõe rigor cientifico. A fantasia é a matéria-prima para uma boa obra em cinema. Podemos concordar com isso. Não podemos concordar, entretanto, que o conhecimento de um povo que juntamente com o branco formou a nação brasileira esteja ausente em todos os momentos do filme, e que este se contente com o humor barato e grosseiro em cima dos estereótipos mais vulgares a respeito deste povo. Não. É inconcebível um cineasta que se diz com "amor do povo" desconhecer esse mesmo povo. O amor pressupõe conhecimento." (Nascimento, 2018: 90). Os debates sobre o filme de Cacá Diegues foram intensos. Respondendo às várias críticas, ele elaborou a expressão "patrulhamento ideológico", que foi posteriormente incorporada no livro Patrulhas ideológicas marca reg.: arte e engajamento em debate / Carlos Alberto M. Pereira, Heloisa Buarque de Hollanda. (1980).

${ }^{3} \mathrm{O}$ acesso a esse texto completo está no livro Beatriz Nascimento, Quilombola e Intelectual (2018), ver bibliografia.

4 Trata-se de uma transcrição de um seminário, promovido pelo SECNEB (Sociedade de Estudos da Cultura Negra no Brasil), em 1981. 
nova identidade é dos Shafts, dos Muhammad Ali, dos James Brown, dos Malcolm $\mathrm{X}$ e outros líderes que representações ou não lutaram para um fim na crise racial americana (Nascimento, 2018:206).

Esse trecho recortado é revelador de um posicionamento político que marcava profundamente o Protesto Negro, num momento em que se articulavam ideias transcontinentais, descolonizadoras e se articulava o debate também no plano da cultura, como continuidade, marcadas as diferenças, desde a Frente Negra Brasileira e o Teatro Experimental do Negro. Enfim, pretendo destacar o papel articulador de Beatriz Nascimento nesses debates sobre as questões raciais, pois assim, sua imagem e voz em Ôrí ficam melhor dimensionadas em sua espessura teórica e política.

Também nos anos 1970, seu texto "A mulher negra no mercado de trabalho" 5 constitui um dos eixos conceituais para o desenvolvimento do feminismo negro. Dessa forma, encontramos na encruzilhada da emergência de uma das faces do pensamento descolonizador da cultura, articulado justamente a partir da evidência de traços negativos da representação de uma personagem feminina, Xica da Silva, e também de uma visão pioneira do que posteriormente viria a compor o campo da interseccionalidade, uma vez que Nascimento, no referido texto, já entrecruzava, opressão de raça, gênero e classe, para pensar a posição dessas trabalhadoras no mercado de trabalho. No trecho, extraído do referido texto, a historiadora diz:

A mulher negra, elemento no qual se cristaliza mais a estrutura de dominação, como negra e como mulher, se vê, deste modo, ocupando os espaços e os papéis que lhe foram atribuídos desde a escravidão. A "herança escravocrata" sofre uma continuidade no que diz respeito à mulher negra. Seu papel como trabalhadora, a grosso modo, não muda muito. As sobrevivências patriarcais na sociedade brasileira fazem com que ela seja recrutada $e$

\footnotetext{
${ }^{5}$ Publicado orginalmente em 1976, no Jornal A Última Hora, do Rio de Janeiro.
} 
assuma empregos domésticos, em menor grau na indústria de transformação, nas áreas urbanas e que permaneça como trabalhadora nas rurais. Podemos acrescentar, no entanto, ao que expusemos acima que a estas sobrevivências ou resíduos do escravagismo, se superpõem os mecanismos atuais de manutenção de privilégios por parte do grupo dominante. Mecanismos que são essencialmente ideológicos e que ao se debruçarem sobre as condições objetivas da sociedade têm efeitos discriminatórios. Se a mulher negra hoje permanece ocupando empregos similares aos que ocupava na sociedade colonial, é tanto devido ao fato de ser uma mulher de raça negra, como por terem sido escravos seus antepassados (Nascimento, 2018:82-83).

Também Raquel Gerber aprofundou os debates sobre descolonização, primeiramente, no âmbito da pesquisa acadêmica, entre outras publicações ${ }^{6}$, lançou $O$ Mito da Civilização Atlântica: Glauber Rocha, Cinema, Política e a Estética do Inconsciente (1982), em que o estético e o político, a psicanálise, a história $e$ as ciências sociais confluíam para pensar as relações entre identidade do sujeito (configurado no cinema de autor) e as relações (e disputas) com a identidade nacional. Aqui, Gerber mira em Glauber, o líder cinemanovista. Em outra vertente, encontramos sua atuação na realização cinematográfica, principalmente, o começo das filmagens de Ôrí, e também a direção do documentário Ilê Xoroquê (1980-81) ${ }^{7}$, filme centrado nas relações temporalmente ancestrais entre a pessoa e o seu orixá, num terreiro de candomblé de origem Banto ${ }^{8}$, em São

${ }^{6}$ Entre 1970 e 1980 fez crítica de cinema e ensaio para revistas e jornais nacionais e estrangeiros como Argumento, Ensaios de Opinião, Filme e Cultura, Suplemento Cultural de O Estado de São Paulo, Cadernos do $3^{\circ}$ mundo e Revista Autrement

${ }^{7}$ Ficha técnica do filme: Ilê Xoroquê (Brasil, 1981, cor, 34'), direção: Raquel Gerber; fotografia: Pedro Farkas, Hermano Penna, Raquel Gerber; som: Walter Rogério, Lia Camargo e montagem: Sérgio Marcelino.

${ }^{8}$ É preciso considerar que muito terreiros de candomblé banto cultuam os Nkisis (inquices) e a língua dos rituais é o kimbundu. 
Paulo. Esse documentário, juntamente com Ôrí e, posteriormente, com outro documentário co-dirigido com Cristina Amaral, Abá $(1992)^{9}$, compõem um longo processo de vivência e criação com o legado afro-brasileiro, em que pesa a atenção sobre os ritos do candomblé. Nesse universo, a energia do Axé (Asé em iorubá), a força sagrada dos Orixás, é compreendida como o elemento que determina as relações entre os seres consigo mesmos e a natureza, compondo uma cosmogonia afrocentrada de grande importância espiritual e também potente para compreender a resistência dos povos da diáspora. Raquel Gerber compartilhou sua síntese desse processo:

Realizei 3 filmes sobre as culturas negras no Brasil em sua relação com as culturas e filosofias africanas. Ylê Xoroquê é o primeiro filme desta trilogia. Ele trata da confirmação da identidade de 2 yaôs (iniciadas), que no Ylê Xoroquê passam por uma iniciação de confirmação de seu ÔRÍ e do pertencimento de cada ÔRÍ ao seu orixá de cabeça: uma de Xangô e uma de Ossanha. Elas não aparecem no filme Ôrí. Só o pai de santo, Babalorixá Táta Wndembeoacy do terreiro (tradição Angola Muchicongo), é que volta em Ôrí. E o filme Abá (curta) fala da concepção filosófica da energia vital para os africanos. Este filme Ylê Xoroque é o início de uma reflexão sobre o desenvolvimento da consciência humana numa concepção africana de mundo. Nele há uma confirmação do pertencimento do indivíduo a um determinado reino da natureza. Em Ôrí a consciência do homem de origem africana já é faceada do ponto de vista sócio histórico, sócio-político e da questão do poder ligado à ideologia do Quilombo. ${ }^{10}$

${ }^{9}$ Ficha técnica do filme: Abá (Brasil, 1992, cor, 4'), direção: Raquel Gerber e Cristina Amaral; fotografia: Raquel Gerber, Hermano Penna e Pedro Farkas; montagem: Cristina Amaral; som: Lia Camargo; produção: Rose Ferreira e Ignacio Gerber.

${ }^{10}$ Conteúdo enviado por email, dia 11 de junho de 2019. 

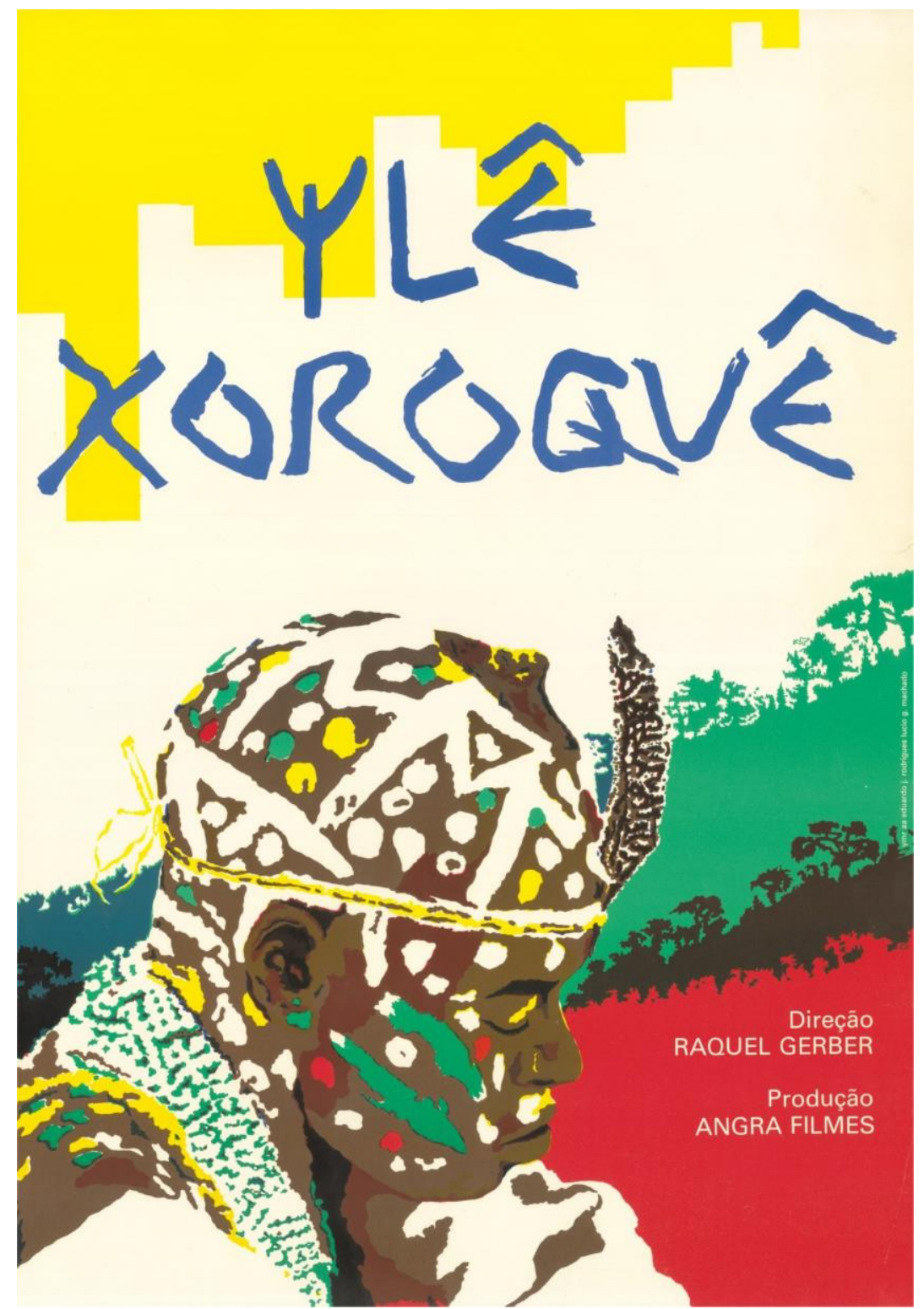

Imagem 01: Cartaz do documentário Ilê Xoroquê (Acervo pessoal de Raquel Gerber). 


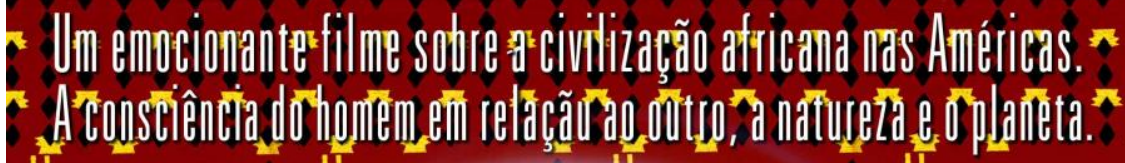
|

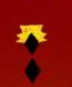

$\int_{4}=2$
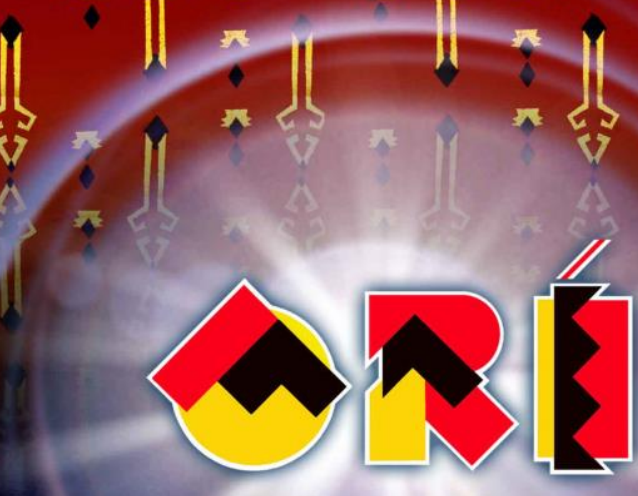

군. \|
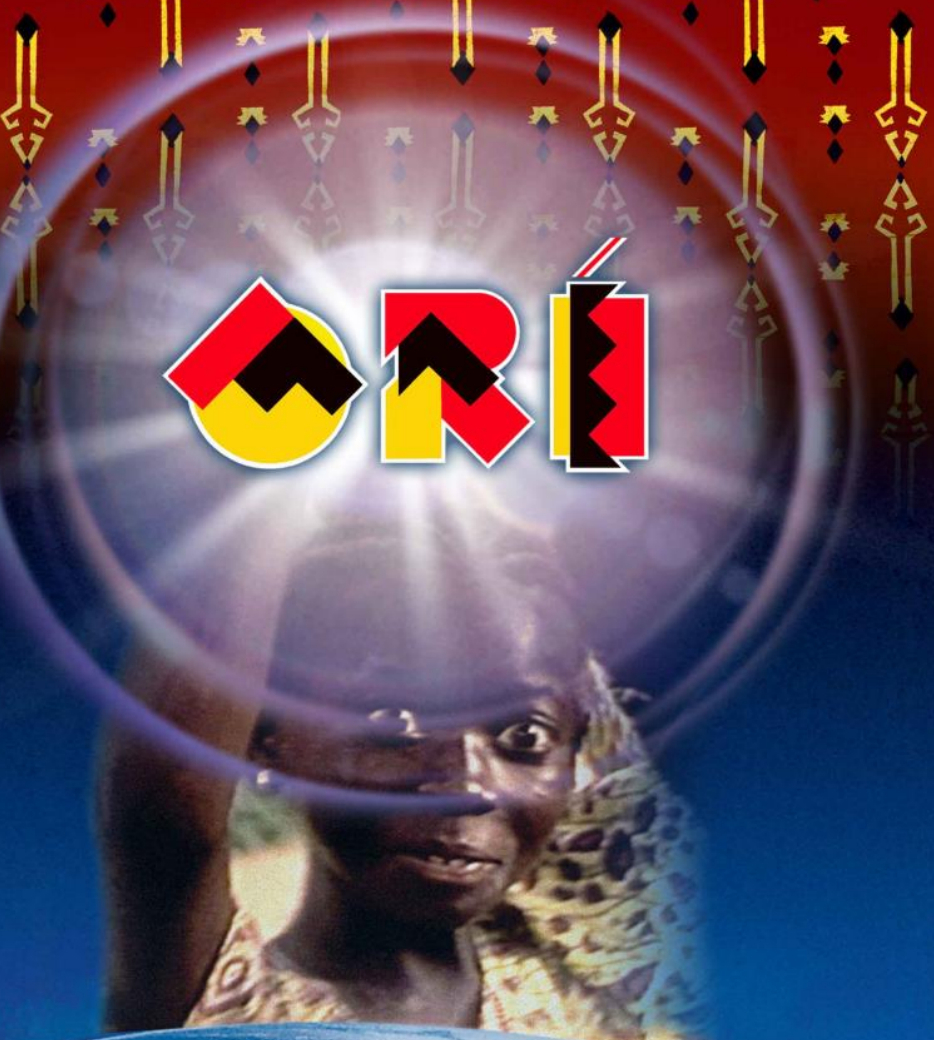

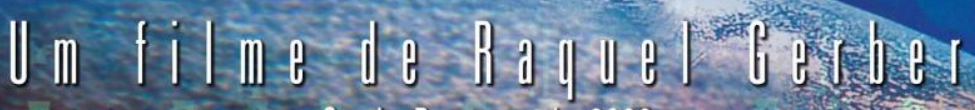
Copia Restaurada 2008

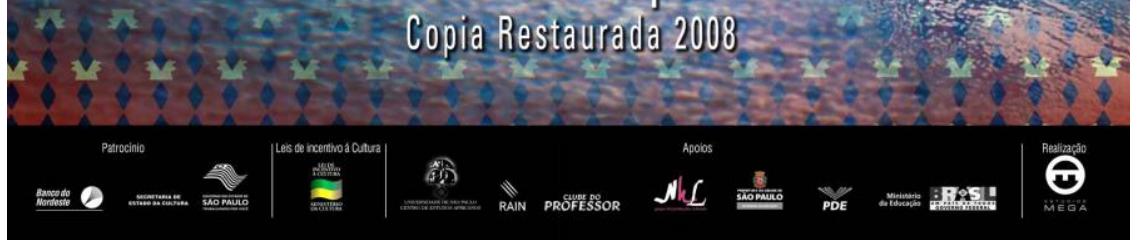

Imagem 02: Cartaz do documentário Ôrí (Acervo pessoal de Raquel Gerber). 
O olhar artístico e o espírito crítico de Raquel Gerber, portanto, aprofundaram-se sobre as questões da descolonização em atenção ao universo do negro, focalizando em expressões culturais e religiosas e processos políticos emergentes de movimentos sociais, rearticulados no contexto da abertura política, que buscavam o reconhecimento da cidadania plena da pessoa negra. No filme Ôrí, o processo criativo vai ao encontro também de uma construção intelectual negra a partir desses mesmos sujeitos, o que gera uma simbiose potente entre imagens $e$ conceitos. Nesse intricado processo, emerge a voz de Beatriz Nascimento, e com ela, suas vivências e pensamento original, compondo um modo radicalmente diferente de pensar as questões da identidade, caras a essa geração.

Em 1989, Beatriz Nascimento escreveu para o lançamento de Ôrí, o seguinte texto ${ }^{11}$ :

ÔRÍ é um filme que participou da vida e da organização do movimento negro da década de 70 . É fruto de encontro de duas pesquisas: cinematográfica (Raquel Gerber) e histórica (Beatriz Nascimento). Iniciando em 1977, centralizado em São Paulo, documenta outros estados e alguns países africanos, fixando nas variadas manifestações da afroamericanidade que brotaram naquele período. Mas ÔRÍ também é um épico, que ao revelar o herói civilizador Zumbi, organizador do Quilombo dos Palmares e sua democracia, reentroniza-o no presente como organizador da consciência negra e por isso vale-se do texto poético. Como tal passeia por múltiplas formas de rituais iniciáticos: os encontros universitários, congressos nacionais $e$ internacionais, as Escolas de Samba, as religiões afrobrasileiras, as sessões de "soul music", trazendo os anseios e os ritmos negros como continuadores da História dos povos africanos da Diáspora. Não é por menos que ÔRÍ, que em Iorubá significa "cabeça", ao realçar o papel dos bantos na sociedade brasileira ao mesmo tempo projeta a

11 Texto enviado ao autor pela diretora Raquel Gerber, via e-mail, em 11/06/2019 (arquivos pessoais da diretora). 
contribuição cosmogônica nagô dos orixás. Por fragmentos que correspondem a processos iniciáticos, se quer um filme reflexivo sobre as atuais condições do planeta: as relações do homem com o outro e consigo mesmo, com a nação e a natureza (Beatriz Nascimento, 10/11/89).

No longo intervalo de elaboração, Ôrí testemunhou e inscreveu em sua narrativa, importantes fatos históricos. Destaco três marcos, o surgimento do Movimento Negro Unificado, em 1978 - o MNU -, nesse mesmo ano definiu-se o Dia Nacional da Consciência Negra, 20 de novembro, e no final da década de 1980, ocorreu o centenário da Abolição em 1988, portanto, esses $e$ outros acontecimentos ataram o filme ao processo de renascimento, reorganização, fortalecimento e debates sobre o movimento negro. No final dos anos 1970, ainda no contexto da ditadura militar, testemunhamos os eventos que denunciavam publicamente o racismo na sociedade brasileira, bem como adensou-se a vontade política de desconstrução e contestação da democracia racial nos cem anos da Lei Áurea, já no período de redemocratização do país. A duração extensa, aliada ao interesse em registrar amplamente pessoas, cenas, eventos culturais, políticos e acadêmicos e lugares no território brasileiro e em países africanos, de maneira tal que se justapunham em um amplo repertório de imagens e sons ligados à cultura afro-brasileira resultou num filme caleidoscópico e longe de oferecer um tratamento linear sobre o tema, houve a preferência em construir uma abordagem multifacetada.

Ôrí nasce do encontro entre essas mulheres e esse universo afrocentrado (Imagem 03). A equipe reunida traz figuras que, desde os anos 1970, marcaram forte presença no cinema e na TV, como Hermano Penna e Jorge Bodanzky na direção de fotografia, além de realizadores que irão despontar no cinema, a partir dos anos 1980, como Walter Rogério (som direto), Pedro Farkas (fotografia), Cristina Amaral (assistência de montagem) e Renato 
Neiva Moreira como montador ${ }^{12}$, somando-se a isso, arrematando a sonoridade, a música original de Naná Vasconcelos. Sua longa duração, no plano da execução, torna o filme emblemático, como testemunha histórica, que incorpora as espessuras e as texturas do tempo e a pluralidade de espaços, no seu desenvolvimento, para narrar sobre processos multifacetados (história, religião, política, cultura etc.) ligados à experiência do negro no Brasil. A voz e as ideias de Beatriz Nascimento, "personagem central do filme" são os fios condutores de um relato bastante complexo.

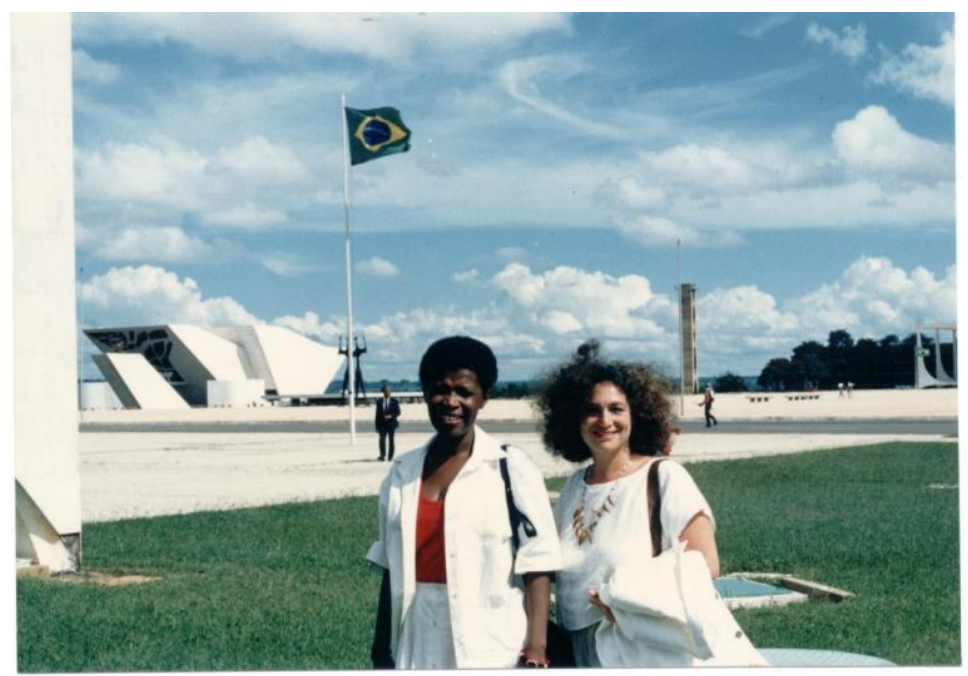

Imagem 03: Beatriz Nascimento e Raquel Gerber, em Brasília, no lançamento do filme, em 1989 (Acervo de Raquel Gerber)

12 Ficha técnica do filme: Orí, Brasil, 1989, cor, 91'. Direção: Raquel Gerber, fotografia: Hermano Penna, Jorge Bodanzky, Pedro Farkas, Adrian Cooper, Chico Botelho, Cláudio Kahns, Jorge Bodanzky, Raquel Gerber, Waldemar Tomas; som: Francisco Carneiro, Lia Camargo, Walter Rogério; montagem: Renato Neiva Moreira; produção: Angra Filmes Ltda., Fundação do Cinema Brasileiro. Ficha técnica completa em: http://bases.cinemateca.gov.br/cgibin/wxis.exe/iah/?IsisScript $=$ iah/iah.xis\&base $=$ FILMOGRAFIA\&lang =p\&nextActi on $=\operatorname{lnk} \&$ exprSearch $=\mathrm{ID}=025653 \&$ format $=$ detailed.pft\#1, acessado em 14 de junho de 2019. 
Assim, sua participação incluiu o registro de sua atuação em debates e aparições públicas e, principalmente, a elaboração do texto do filme, narrado por ela mesma, onde expõe suas reflexões originais sobre as noções de quilombo, por exemplo, e também a irrupção de um tom intimista, próximo ao confessional, que marca a inscrição da auto representação, cara aos documentários autoreflexivos, em contextos diaspóricos (Diawara, 1999). A incorporação da materialidade da voz de Beatriz que, por sua vez, faz comunicar seu próprio corpo e pensamento e os sentidos da continuidade da ancestralidade afro-brasileira traduz um olhar duplamente feminino e feminista sobre a história. Isso se constitui num deslocamento radical pelo transbordamento subjetivo manifesto na narração poética, nas imagens de forte efeito estético e nas músicas selecionadas. Disso, surgiu um documentário interessado numa construção singular sobre a compreensão da diáspora africana e da cultura brasileira, conduzido por uma encenação com imagens transnacionais, arquivos e uma gama plural de registros locais.

Para abordar o filme, os seguintes vieses foram acionados: 1) os efeitos de sentido da voz de Beatriz Nascimento e sua performance conceitual, centrada nas ideias de transmigração $e$ quilombo; 2) a montagem cartográfica que comprime a longa duração da experiência da realização do filme e imprime um forte sentimento de lugar, sendo esse "lugar" os espaços atravessados pelo ser e estar negro no mundo.

\section{A voz de Beatriz Nascimento: performance de si e olhar localizado}

A narração de Beatriz Nascimento, transcrita logo abaixo, abre o documentário. A citação é uma síntese poética que dispara os desdobramentos da diáspora africana no Brasil, o ponto de inflexão denso do filme. Sob a música instrumental de Naná Vasconcelos, uma imagem animada elabora o título do filme, composto em grafismo iorubano. Em seguida, partindo-se de círculos visuais refletidos no visor, pela imagem estourada, com 
forte efeito simbólico (justamente pela sincronia da narração), seguem-se imagens do sol/céu/mar/mata justapostas para compor uma parte da abertura:

A Terra é circular, o Sol é um disco, onde está a dialética? No mar, Atlântico-mãe. Como eles puderam partir daqui para um mundo desconhecido? Aí eu chorei de amor pelos navegadores, meus pais. Chorei por tê-los odiado. Chorei por ainda ter mágoa desta história. Mas chorei fundamentalmente, diante da poesia do encontro do Tejo com o Atlântico, da poesia da partida para a conquista. Eles o fizeram por medo também e talvez tenham chorado, diante de todas as belezas além do mar Atlântico. Oh paz infinita, poder fazer elos de ligação numa história fragmentada. África e América e novamente Europa e África. Angola, Jagas e os povos de Benin de onde vem minha mãe. Eu sou Atlântica!

Nesses primeiros minutos, emerge uma memória mítica da narradora $e$ as imagens $e$ os sons reforçam essa imaginação poética que entrecruza aventura e dor vindos do conteúdo verbal. Um tipo de elaboração que instaura uma subjetividade em que convergem o ponto de vista da câmera (em sintonia musical) e o ponto de vista da personagem narradora. Portanto, a imagem deixa de ser ilustração e a narração não se limita a ser explicação sobre o mundo, ambos compõem o que em termos literários, compreendemos como o discurso indireto livre, porém, no cinema.

Imagens da natureza reforçam o tropo do discurso de formação, um recuo no tempo e a instauração de outra narrativa fundadora. Nesse início, reúnem-se na tela e no som uma urdidura indissociável, entre o estético e o político, algo que se reforça à medida que o filme evolui, nutrindo um processo de reflexão nomeado como um olhar localizado (Haraway, 1995). Desse modo, essa assertiva - "Eu sou Atlântica" - conduz o espectador por uma dominante narração, escrita por quem narra, Beatriz Nascimento, uma militante e intelectual negra brasileira, $e$ 
juntamente ao "como" se narra, temos a problemática "sobre o que" se narra: o ponto de vista de uma historiadora sobre a diáspora, de uma perspectiva pessoal, em fina sintonia com o processo de observação e análise sobre acontecimentos, atores $e$ atrizes sociais, conceitos e os processos que resultaram da tríade colonização/escravidão/libertação. Toda essa costura sob a sonoridade de uma percussão que conecta ancestralidade $e$ arremata o tom do início de outra história, para disputar com narrativas já conhecidas.

Configura-se, então, um corpo articulado à fala sobre si, algo, de antemão, que repõe/propõe um tipo de participação específica no universo do documentário: as performances de si. Especificamente, em Ôrí, essa performance pessoal, no documentário, incursiona por dilemas identitários, estando à frente, a principal personagem, Beatriz Nascimento. Assim, sob sua voz, é recontada brevemente a origem da formação cultural do Brasil, por meio de uma mudança radical na abordagem. Assume-se a contribuição dos povos africanos para a construção das "Américas", $e$ as belas imagens das águas do Atlântico, mapas $e$ brasões de Portugal e de povos da África se atam à voz da narradora para uma exposição poética daquilo que ela mesma concebe como civilização transatlântica. O deslocamento é radical na medida em que a diáspora africana não é considerada apenas pelo deslocamento de homens e mulheres como escravos, e sim constituiu-se na formação de uma cultura híbrida, transnacional, atualizada pelo encontro de povos de distintas origens. Essa visão da cultura afro-brasileira, enfatizada pela dimensão do deslocamento e da diáspora surge como um elemento singular do documentário, e olhando-o no conjunto da produção audiovisual, sua distinção torna-se evidenciada, dada a espessura conceitual que embala suas asserções.

Essa opção, pela narração que considera a cultura afrobrasileira em perspectiva diaspórica, promove um certo distanciamento em termos de abordagem em relação aos outros relatos audiovisuais do mesmo interesse temático. Por exemplo, na esfera do vídeo, obras como Raça Negra, de Nilson Araújo 
(1988), Se o Rei Zulu já não pode andar nu (1987), de Rita Moreira e Maria Lucia Silva, Mulheres negras (1986) de Márcia Meireles e Silvana Afram (Lilith Vídeo), Axé (1988), de Márcia Meireles e Maria Angélia Lemos (COMULHER - Comunicação Mulher), Eu, mulher negra, de Joel Zito Araújo (1994) e as produções do Enugbarijo Vídeo (documentários produzidos e dirigidos por Ras Adauto e Vik Birkbeck), Mulher negra TV TV TV (1985) e As Divas Negras do Cinema Brasileiro (1989), contemporâneos a Ôrí, dão uma breve amostragem do interesse dessa geração pelas questões afro-brasileiras, sendo que chama a atenção a conjunção entre gênero e raça, conforme enunciado em alguns títulos e o recorte sincrônico, enfatizando a problemática negra no presente dos filmes, certamente com alguns recuos explicativos, com grande valorização das pautas advindas de movimentos sociais, de onde essa produção se vinculava diretamente.

No campo do longa-metragem, juntamente com Ôrí, outros documentários também demonstraram o interesse em falar sobre o negro justamente no centenário da Abolição, 1988, período fortemente marcado pela denúncia das desigualdades sociais que afetam a população afro-brasileira e que sufocaram, de certa forma, as tentativas de celebração oficiais. Refiro-me a Abolição, de Zózimo Bulbul (1988) e O Fio da Memória, de Eduardo Coutinho (1994). Dois relatos importantes e que, juntamente com o documentário de Raquel Gerber, oferecem uma ampla visão sobre as questões identitárias, políticas, econômicas, sociais e culturais do povo negro, operando em chaves diferenciadas. Assim, as produções do movimento do vídeo atinham-se aos esquemas do engajamento e da denúncia, e os longas-metragens de Bulbul e de Coutinho enfatizaram o espaço de tempo entre o fim da escravidão e o centenário da Abolição, forjando um quadro crítico que, embora coloquem em evidência as questões da negritude de forma crítica, preservam a expressão audiovisual centrada em entrevistas e depoimentos. Nesse sentido, todas realizações consideradas se aproximam do modo interativo de realização documentária. 
Em sua estruturação, Ôrí inscreve materialmente a voz de Beatriz Nascimento, em que ela comunica seus pensamentos próprios sobre a diáspora $e$ os sentidos particulares que a ancestralidade assume no Brasil. Ela escreveu seu próprio texto e narrou suas próprias ideias, algo que contingencia o pessoal, o político e o estético como abordagem. Aqui, em sintonia com Paul Gilroy, que na década de 1990 iria lançar seu influente $O$ Atlântico Negro, temos essa conjunção de ideias sobre as considerações sobre a diáspora como veio para a compreensão de uma visão não essencialista sobre a raça. Para Paul Gilroy:

\begin{abstract}
[...] a diáspora desafia isto ao valorizar parentescos sub $e$ supranacionais, e permitindo uma relação mais ambivalente com as nações e com o nacionalismo. A propensão não nacional da diáspora é ampliada quando o conceito é anexado em relatos antiessencialistas da formação de identidade como um processo histórico e político, e utilizado para conseguir um afastamento em relação à ideia de identidades primordiais que se estabelecem supostamente tanto pela cultura como pela natureza. Ao aderir à diáspora, a identidade poder ser, ao invés disso, levada à contingência, à indeterminação e ao conflito (Gilroy, 2001:19).
\end{abstract}

Beatriz Nascimento, ainda nos primeiros minutos, diz: "Foi transportado para América um tipo de vida que era africana. É a transmigração de uma cultura e de uma atitude no mundo, de um continente para outro, de África para América." Sobre esse termo transmigração, Alex Ratts elabora a seguinte reflexão:

Para Beatriz Nascimento o corpo negro se constitui e se redefine na experiência da diáspora e na transmigração (por exemplo, da senzala para o quilombo, do campo para a cidade, do Nordeste para o Sudeste). Seus textos, sobretudo em Ôrí, apontam uma significativa preocupação com essa (re)definição corpórea. Neste tema, a encontramos discorrendo acerca da sua própria imagem, da "perda da imagem" que atingia os(as) escravizados(as) e da 
busca dessa (ou de outra) imagem perdida na diáspora (Ratts, 2006:65).

Ao recuperar o termo transmigração, situando-o no pensamento diaspórico e relacionando-o, por exemplo com Paul Gilroy, podemos enxergar "formas geopolíticas e geoculturais" (Gilroy, 2201:25) resultados de interações. Agrega-se ao termo, outro forte investimento conceitual de Beatriz Nascimento, que plasma no filme suas pesquisas sobre os quilombos:

O quilombo surge do fato histórico que é a fuga, é ato primeiro de um homem que não reconhece que é propriedade de outro, daí a importância da migração, da importância da busca do território. Então, naquele momento quando se estabelece na floresta tropical do Nordeste do Brasil e depois em algumas regiões do Brasil inteiro, principalmente em Minas Gerais, Bahia e no final do século passado em São Paulo. Ele estabelece um sentido de nação estritamente africano e Banto, a nação aculturada. Essa textura do Banto, essa rede de relações que o Banto estabelece na África, entre as várias etnias, está fundamentada na própria raiz da língua Banto, que é a raiz NTU. O sentido de NTU é a relação de pessoa para pessoa. Os homens se comunicam através daquela raiz e se conhecem entre si, na África, por esse radical da sua própria língua nacional (Transcrição do filme).

E, ainda:

O quilombo é memória que não acontece só para os negros, acontece para a nação. Ele aparece, ele surge nos momentos de crise da nacionalidade. A nós não nos cabe valorizar a história. A nós cabe ver o continuum dessa história. Porque Zumbi queria fazer a nação brasileira, já com índios e negros integrados dentro dele. Ele queria empreender um projeto nacional de uma forma traumática. Mas não tão traumática quanto os ocidentais fizeram, 
destruindo culturas, destruindo a história dos povos dominados (Transcrição do filme).

Beatriz Azevedo foi uma das principais pesquisadoras dos quilombos no Brasil. Seu interesse e desenvolvimento de pesquisas sobre esse tema convergem, no mesmo contexto histórico, com as pesquisas e publicações de Abdias Nascimento e seu impulso pelo quilombismo. ${ }^{13}$ Conforme os trechos transcritos, entre outros presentes no filme, ela apresenta sua visão que conecta o espaço da fuga e da resistência com o movimento da história. Para Beatriz, os quilombos se atualizariam nos espaços contemporâneos habitados pela população negra $e$ isso estaria conectado com o propósito político de forjar uma nova perspectiva da história do negro. Em primeiro lugar, desprendendo-o da ideia que somente o relaciona como força de trabalho e essa tomada de consciência se atualizaria na própria palavra Ôrí, o título do filme, de origem iorubá que quer dizer "cabeça" e está conectada com o "fazer a cabeça" na iniciação do candomblé. Assim, a ideia contemporânea do quilombo, o fazer a cabeça e a defesa de uma civilização do Atlântico, marcada por trocas culturais, conectam o filme a uma discussão identitária transnacional e à medida que o documentário avança, essa carga identitária vai também se libertando para uma visão mais holística das relações entre as pessoas, chegando, inclusive, a um estágio de superação do que é ser negro, nos limites do movimento negro.

Finalmente, como algo próximo a uma síntese, eu gostaria de destacar 03 eixos que singularizam o documentário em sua performatividade, como desdobramentos das ideias de transmigração e de quilombo para o filme:

13 O livro O quilombismo. Documentos de uma militância pan-africanista, de Abdias Nascimento (2019) é uma publicação que reúne textos escritos e tornados públicos em distintos contextos, mantendo como unidade estrutural a denúncia do racismo e os modos de articulação da supremacia branca, avançando para reflexões aprofundadas sobre processos históricos de opressão e a luta pela libertação do negro, sobretudo, de abordagem cunho pan-africanista. 
Primeiramente, chamo a atenção para um particular tipo de feminismo apresentado, o feminismo negro. No contexto do renascimento dos movimentos sociais do negro, nos anos 1970, Beatriz Nascimento, Thereza Santos e Lélia Gonzalez eram ao mesmo tempo ativistas políticas e intelectuais negras bastantes influentes. As vozes e o pensamento de Beatriz e de Thereza ecoam no documentário. Em suas lutas e posicionamentos, elas e outras mulheres não se identificavam com a mesma herança racial, condição social, vida cultual $e$ a história do chamado feminismo universal. Assim, definiram e defenderam a ideia do feminismo negro, no qual as lutas de mulheres eram interseccionadas com categorias raciais e de classe e também com as histórias de vida das populações subrepresentadas, numa defesa de que caberia à mulher negra assumir o pessoal $e$ o político, justamente no esforço de construir e protagonizar uma história que lhe foi negada até então.

$\mathrm{O}$ segundo eixo diz respeito às tensões entre invisibilidade $e$ visibilidade. Numa das sequencias do documentário, durante a Quinzena do Negro, na Universidade de São Paulo, Beatriz Nascimento diz "A questão econômica não é o grande drama (...) O grande drama é o reconhecimento da pessoa negra que nunca foi reconhecida no Brasil". Num outro momento, as sequencias de fotografia dela e sua família configuram uma inscrição à parte em um conjunto de imagens do repertório do filme, e ouvimos uma narração fortemente questionadora em relação ao desejo de ser pela imagem. Para Beatriz Nascimento, "é preciso a imagem para recobrir a identidade".

Conectados a sua voz over e ao seu texto incisivo, surge primeiramente na tela uma imagem de fotografia $3 \times 4$ - "neste momento, pela imagem, eu não sei quem sou", ela diz - $e$ completa o pensamento dizendo que a "invisibilidade está na raiz da perda da identidade". Em outras imagens, outras questões surgem, não menos contundentes: uma fotografia de primeira comunhão, a foto de sua irmã e uma fotografia da família reunida. Seguimos uma narração em que questões sobre imagem $e$ pertencimento e imagem e identidade são amarradas na narrativa 
que inspeciona de forma ampliada e densa sobre "os lugares do negro", na sociedade, na história, na cultura e nas imagens.

Finalmente, inscrevem-se no filme as consequências da diáspora e a interminável construção da identidade. Aqui, testemunhamos um esforço artístico e intelectual pioneiro para um mundo pós-racializado, sustentado por uma consciência ecológica no qual a palavra Ôrí, e por extensão seu conceito, é uma conexão central e potente entre mundos, entre Brasil, África e o planeta Terra.

Década depois dos escritos e pronunciamento de Beatriz e do lançamento de Ôrí, o filósofo camaronês e estabelecido na África do Sul, Achille Mbembe, em sintonia com essas prerrogativas, sintetiza:

De fato, para aqueles que passaram pela dominação colonial ou a quem, num dado momento da história, a sua humanidade foi roubada, a recuperação desta parte da humanidade passa muitas vezes pela proclamação da diferença. Mas, como vemos em certa crítica negra moderna, a proclamação da diferença é apenas um momento de um projeto mais vasto - de um mundo que virá, de um mundo antes de nós, no qual o destino é universal, um mundo livre do peso da raça $e$ do ressentimento $e$ do desejo de vingança que qualquer situação de racismo convoca (Mbembe, 2014:306).

Raquel Gerber parece, assim, compartilhar, nessa experiência dialógica com o pensamento de Beatriz, ou seja, para ela é uma busca contínua pela libertação do negro, inclusive do termo negro, "o negro que está em todos os lugares, o movimento não é o do negro é o da história" (transcrição do filme).

\section{2) A montagem: cartografia de emoções políticas em Ôrí.}

O fundamento do quilombo é a terra, o homem se identificando profundamente com a terra. Então, o Ebó é dado para a terra, todos os elementos vivos estão na terra $e$ 
vão participar daquele banquete que é o Ebó. Quer dizer, vai ter ali vírus, vai ter ali micróbios, vai ter ali células que vão se decompor e se transformar em outras células... e esse é o princípio do 'axé', da força. (voz over de Beatriz Nascimento, transcrição do filme)

Ôrí é um filme marcado por vastos deslocamentos, em múltiplos territórios e geografias, enfim, uma gama de atravessamentos e estabelecimentos espaciais, em sintonia com a espessura temporal de sua execução. Portanto, uma relação espaço-temporal dilatada, ao mesmo tempo fortemente vivida, em que acompanhamos transformações profundas da negritude na diáspora e em conexões com países africanos. Um filme de viagem, cuja travessia move seus sujeitos participantes e também conduz os espectadores para algum lugar. Dessas incidências disparam-se visões de mundo descolonizadoras, feministas $e$ negras numa forma fílmica singular, em suas imagens e sons. Transmigração e quilombo constituem-se em eixos centrais das ideias de Beatriz Nascimento compartilhadas em sua narração. Ambos termos conectam-se com ideias de espaço e tempo em seus usos, e conforme se nota, modificam conceitos estabelecidos de identidade e território, numa ótica feminina. Dito isso, num processo comparativo para fins de análise, acredito, que as intricadas relações que nascem desse filme ganham luz quando colocadas em perspectiva, a partir das ideias de Giuliana Bruno e seu livro Atlas of Emotion - Journeys in Art, Architecture, and film (2002). Trata-se de um ensaio em que confluem artes visuais, arquitetura e cinema, sendo o elemento disparador da reflexão, sua fonte de inspiração, o imaginário produzido pela escritora francesa Madeleine de Scudery, que desenha um mapa para seu romance Clélie, do século XVII:

Sua Carte du pays de Tendre - um mapa da terra da ternura - retrata um terreno variado, composto por terra, mar, rio e lago $e$ inclui, juntamente com algumas árvores, algumas pontes e várias cidades. O mapa, produzido por uma personagem feminina do romance para mostrar o 
caminho para os "países de ternura", incorpora uma viagem narrativa. Ou seja, visualiza, sob a forma de paisagem, um itinerário de emoções que, por sua vez, é o topos do romance. Dessa forma, a Carte de Tendre torna visível um mundo de afetos. Em seu design, desenvolvido a partir de uma jornada amorosa, o mundo exterior transmite uma paisagem interior. A emoção se materializa como uma topografia em movimento. Atravessar essa terra é visitar o fluxo e refluxo de uma psicogeografia pessoal e social (Bruno, 2002:02, tradução minha). ${ }^{14}$

Aqui, estabelece-se uma relação afetiva com o espaço, que é algo caro ao processo de enunciação de Ôrí. Giuliana Bruno, a partir desse universo de confluência entre o literário, o cartográfico e a imagem do atlas, explora as relações hápticas no campo da representação, especificamente, os elementos que mobilizam o sentido tátil, nas relações espaciais. Ela vai além, justamente para relacionar o háptico à capacidade dos corpos em se movimentarem conscientemente no espaço. Portanto, para a autora, há uma lógica geográfica e cultural nessas relações espaciais, o que ativa uma relação mais complexificada do sujeito com os espaços habitados, com o ambiente no campo das representações, inclusive o cinema, comumente referido em sua natureza dominantemente visual. Nesse sentido, ao considerar o cinema, a autora interessa-se pela genealogia das emoções, já que a palavra emoção contém em sua raiz a ideia de movimento, o que gera um circuito ativo de movimento, afeto e tato, segundo sua lógica. Diz ela que

14 "Her Carte du pays de Tendre - a map of the land of tenderness - pictures a varied terrain comprised of land, sea, river, and lake and includes, along with some trees, a few bridges and a number of towns. The map, produced by a female character of the novel to show the way to the "countries of tenderness", embodies a narrative voyage. That is, it visualizes, in the form of a landscape, an itinerary of emotions which is, in turn, the topos of the novel. In this way, the Carte de Tendre makes a world of affects visible to us. In its design, grown out of an amorous journey, the exterior world conveys an interior landscape. Emotion materializes as a moving topography. To traverse that land is to visit the ebb and flow of a personal and yet social psychogeography" (Bruno, 2002:02). 
apresentarei como premissa principal do atlas que o movimento, de fato, produz emoção $e$ que, correlativamente, a emoção contém um movimento. É esse princípio recíproco que move o livro inteiro, moldando o caminho háptico que percorre suas várias jornadas culturais (Bruno, 2002:6-7, tradução minha).

Interessa reter esse olhar que preza pelo háptico, que ocupa o território, movimenta-se e se emociona. Lembrando que a palavra emoção está diretamente relacionada às ideias de movimento, de transformação.

Há mapas, panorâmicas, tomadas aéreas, câmera na mão, planos gerais e outros indicadores visuais de um traçado espacial, que demonstra o interesse por rotas, mapeamento e localização em Ôrí. O interesse por paisagens é intenso, observá-las é também atribuir sentido, pela narração, pela música, pela observação. $\mathrm{O}$ documentário promove, dessa maneira, deslocamentos significativos e rotas planejadas, mas a duração de sua execução também embute o acaso como elemento potente para deixar-se contaminar por encontros inesperados. O resultado é uma montagem cartográfica que posiciona os sujeitos no mundo, organiza-os, traça itinerários e atribui significados nas relações espaço-temporais. Tato, movimento e emoção, aqui, a emoção é política, pois o que se estabelece é, no sentido figurado, uma ocupação estratégica por parte de sujeitos que foram durante séculos, primeiramente, confinados como escravos durante a diáspora, posteriormente, subrepresentados, e no presente do filme, há esse movimento político de afirmação de uma identidade por meio do atravessamento oceânico. O filme, em sua montagem, atualiza o fenômeno da transmigração, pontuado por Beatriz Nascimento, e sinaliza a convergência entre os continentes Americano, Europeu e Africano, compondo o que a historiadora denomina a civilização transatlântica. Dessa dimensão transcontinental, emerge essa compreensão estética e política dos territórios-quilombos. 


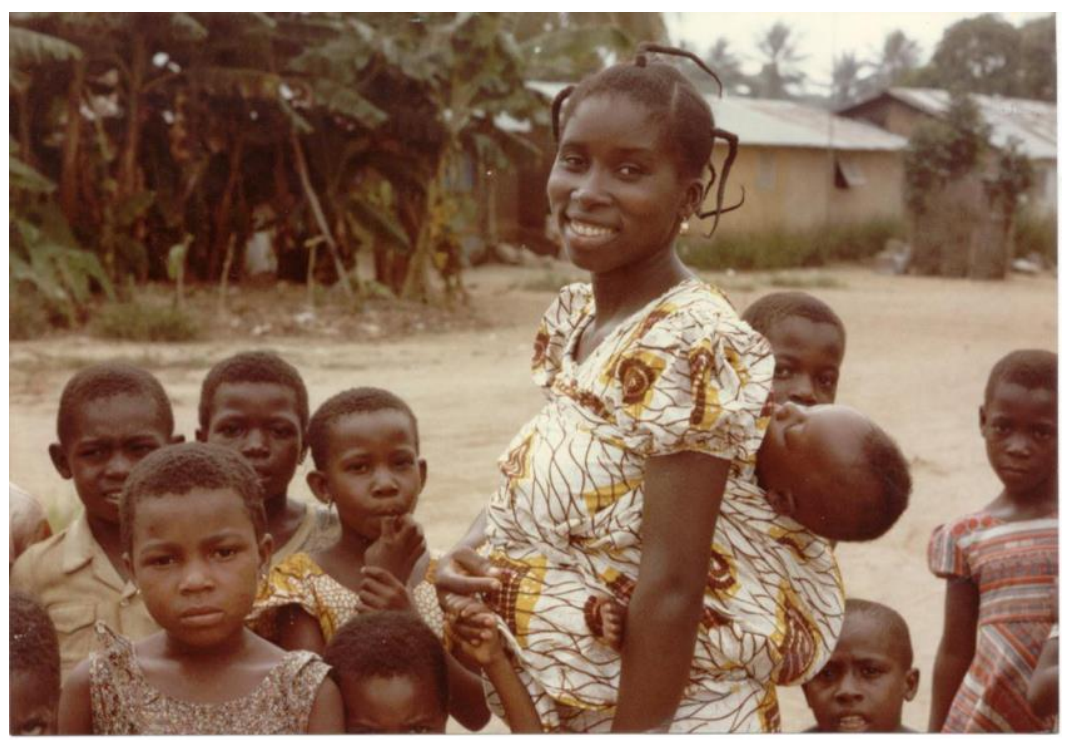

Imagem 04: Stilll do documentário Ôrí.

Exemplos de trânsitos espaço-temporais podem ser vistos nas primeiras imagens do filme, o que dá uma dimensão desses deslocamentos radicais, das geografias africanas, onde se observam paisagens e povos de países tais como Senegal, Angola e Mali, em seguida, avança-se para um espaço de herança banto, na cidade de São Paulo, onde acontece uma incorporação de Exu, por Pai Wndembeoacy, no terreiro Ilê Xoroquê e, depois, momentos da "Quinzena do Negro", ocorrida na Universidade de São Paulo em 1977. Importante destacar o registro de intervenções breves e pontuais de diferentes pessoas que compõem o debate sobre negritude no final dos anos 1970, e estão reunidos nesse mesmo evento: Eduardo Oliveira e Oliveira, sociólogo, Marcelo Orlando Ribeiro, da Frente Negra Brasileira, e a antropóloga e cineasta Juana Elbein dos Santos, coordenadora geral da Sociedade de Estudos da Cultura Negra no Brasil SECNEB.

O filme compõe em sua montagem uma cartografia solta, mosaicada, mas palpável em sua dimensão háptica para conduzir 
o espectador nesse processo simbólico de ocupação territorial. Daí os recortes fixam-se em sequencias demoradas nos bailes Black, observando-se danças coletivas, cabelos e roupas, modos de comportamento da juventude em diálogo com extratos internacionais, num contágio pop-pan-africanista como sugerem as imagens de Jimmy Cliff, Gilberto Gil e a banda Black Rio, entre outras. Imagens da Escola de Samba Diplomatas de São Miguel Paulista e da Vai-Vai informam sobre heranças africanas e sua atualização nos ritos e na ocupação territorial, a primeira faz um desfile com o tema "Os Dogons - Raízes da Cultura AfroBrasileira", evocando o dogons, ponto original de onde surgiram outras culturas africanas, e a Vai-Vai, inscrita em várias sequencias, é a síntese da escola de samba como quilombo, desde a ocupação original do Vale do Saracura, no Bixiga, região central de São Paulo.

É preciso considerar que a heterogeneidade de imagens e sons e os eventos que eles expressam informam sobre o campo da negritude contemporânea do filme. Isso demonstra o plano da diversidade inerente a essa configuração. Dos vários extratos amalgamados nessa épica, a atenção ao movimento negro deve ser destacada. O filme emerge da irrupção do Movimento Negro Unificado - MNU (1978). Nomes militantes inscrevem-se no filme, com pequenos e contundentes registros e depoimentos, nas figuras históricas de Abdias Nascimento, Thereza Santos, Hamilton Cardozo entre outros. E nos descolamentos, andanças e viagens do filme, estão registros de momentos de encontro político, que marcaram o renascimento dos movimentos sociais dos negros, cito: FECONEZU - Festival Comunitário Negro Zumbi, em São Carlos, em 1980; a reocupação da Serra da Barriga - União dos Palmares, em Alagoas; o III Congresso de Cultura Negra das Américas São Paulo, em 1982, que reuniu Abdias Nascimento, Marvin Wright Lindo, liderança da Costa Rica, Jose Correia Leite, da Frente Negra Brasileira e Don Rojas, militante e jornalista de Granada, para citar alguns. Esse evento político foi aberto com a presença novamente de Pai Wndembeoacy, do Ilê Xoroquê, que 
faz a evocação a Exu, o senhor mensageiro. E as imagens atestam essa união entre o político e o espiritual, de herança ancestral.

No Ôrí (cabeça) pontua-se o novo estágio da vida, por meio do encontro do sujeito com seu orixá, mediante a iniciação. Os orixás são cultuados em terreiros de candomblé, ponto alto da resistência africana na diáspora afro-brasileira, e no Brasil, originário da herança banto, também se cultuam os caboclos. Essa entidades místicas, orixás, caboclos e Exu estão presentes no filme $e$ adensam a rede de diferentes modos de ser e estar negros no território, a formação de quilombos e sua experiência, que alude à vida comunitária. Cantar e dançar juntos, comer juntos. O sentido da agregação coletiva negra nesses espaços fazem vibrar essa relação do tato com o solo, a comida (comer com as mãos, muitas vezes), dançar, abraçar, cantar, estar junto. E dessa conjunção de corpos unidos, compondo também, em continuidade de uma experiência-quilombo no mundo, também está a capoeira: "Há umas coisas da cultura negra que não estão sendo registradas, como, por exemplo, uma frase como essa que é da capoeira, de Angola, que diz: 'Vou chegando devagar'. Isso é uma coisa que está muito no ETHOS da comunidade negra, no seu comportamento físico, psicológico, diante do real. Então, ele chega devagar, ele chega se dando. 'Meu amigo companheiro, eu vou chegando devagar" (Transcrição do filme). Esse emaranhado de referências constitui como um assentamento em que as imagens, os sons, os territórios, os corpos e os acontecimentos comunicam sobre o ser e estar negro.

\section{Ôrí: lições da negritude}

Raquel Gerber elabora um filme de viagem, com contornos muito singulares. Essa dimensão da viagem que se incorpora ao trabalho artístico, por meio de uma câmera anti-naturalista, conecta-a aos domínios do filme ensaio (Rascaroli, 2008; Corrigan, 2011), o filme é denso na carga subjetiva e performática ao apresentar seu conteúdo, o que não diminui seu vigor político $e$ estético, ao contrário, faz vibrar esses dois elementos de forma 
fragmentária e porosa, oferecendo ao espectador a potência das conexões e dos fluxos não lineares. Desse modo, estão articulados e enviesados caminhos já trilhados pela etnografia experimental $e$ pela antropologia cultural. Assim, sua maneira de ver o mundo não se confunde com os procedimentos descritivos tradicionais das ciências humanas, mas se colocam como formas de dialogar, intervir e questionar esse mundo observado e enquadrado pelos dispositivos de gravação de som e imagem e arquivos, buscando formulações próprias no conteúdo na expressão audiovisual. Há, assim, uma conexão com nomes tais como Dziga Vertov, Jean Rouch, Chris Marker, Trinh T. Minh-h, Isaac Julian e John Akomfrah, sendo algo comum o interesse pelos deslocamentos humanos e suas tensões, a atenção e a reflexão no âmbito das diásporas, a desarticulação de estruturas de linguagem préestabelecidas, o trabalho com arquivos. Tal como esses artistas, o trabalho da cineasta se apresenta como um olhar atualizado sobre as questões de seu tempo.

O encontro com Beatriz Nascimento e a construção de uma jornada da narradora fundam, no horizonte do cinema brasileiro, uma épica feminina negra. O processo de condução da narração que traz à frente um campo de ideias e conceitos da própria narradora, e que também circulam em espaços acadêmicos $e$ midiáticos, e também inclui um repertório íntimo, privado, de sentimentos pessoais e compartilhamento de laços afetivos resultam num ponto de vista entendido como um distanciamento apaixonado. Aqui a exterioridade e a interioridade se imiscuem numa rede de afecção, sendo o estatuto da voz over radicalmente diferente de toda a tradição documentária brasileira até então. $\mathrm{O}$ filme, desse modo, inaugura a voz da mulher negra no cinema, plenamente falando $e$, juntamente com essa voz, instaura um olhar específico sobre a história, num cruzamento entre o de fora $e$ o de dentro potentes, próximo ao que será, posteriormente nomeado por bell hooks como o olhar opositor:

Que todas as tentativas de reprimir o nosso direito - das pessoas negras - de olhar produziram em nós um desejo 
avassalador de ver, um anseio rebelde, um olhar opositor. Eu quero que meu olhar mude a realidade. Mesmo nas piores circunstâncias de dominação, a habilidade de manipular o olhar de alguém diante das estruturas de poder que o contém abre a possibilidade de agência (hooks, 2019:216).

E a orquestração desse olhar/voz se dá por uma conjunção complexa entre extratos sonoros e imagéticos plurais. É preciso considerar, sobretudo, que o ponto de vista do filme, é dominantemente atravessado por compartilhamento de experiências e reflexões de uma mulher intelectual negra, em que se estabelece um posicionamento crítico e questionador da história e da realidade, ao mesmo tempo, que reorganiza esses extratos, resultando nas incursões opositivas, em relação às normas cinematográficas, que é esse mesmo processo. Para efeitos de análise, entendemos que a noção de montagem cartográfica é potente para compreender o trabalho de justaposição e também de condensação das vivências com o renascimento do movimento negro e seus percursos nos anos considerados, no documentário. Trata-se, aqui, de um trabalho de combinação de espaços $e$ tempos diversos, que atualizam a ideia de civilização transatlântica, efeito da transmigração, portanto, movimentos que sempre fazem voltar para o ponto de vista de sua enunciadora principal. E ao unir no mesmo espaço fílmico vivências $e$ experiências caras à compreensão da negritude brasileira em conexão o Black Power, a Negritude e o Pan-africanismo, a montagem resulta em um trabalho estético amalgamado às políticas identitárias, compreendida, em síntese, como a reinvindicação da plena cidadania de sujeitos negros.

\section{Referências bibliográficas}

BRUNO, Giuliana. Atlas of Emotion: Journeys in Art, Architecture, and Film. New York, Verso, 2002.

CORRIGAN, Timothy. The essay film: from Montaigne, after Marker. Nova Iorque, Oxford University Press, 2011. 
DIAWARA, Manthia. The "I" Narrator in Black Diaspora Documentary. In: KLOTMAN, Phyllis; CUTLER, Janet. Struggles for representation: African American Documentary Film and Video. Bloomington, Indiana University Press, 1999.

GERBER, Raquel. O mito da civilização atlântica: Glauber Rocha, cinema, política e a estética do inconsciente. São Paulo, Vozes Secretaria de Cultura de São Paulo, 1982.

GILROY, Paul. O Atântico Negro. Modernidade e dupla consciência. Rio de Janeiro, Editora 34 e Universidade Cândido Mendes - Centro de Estudos Afro-asiáticos, 2012.

HALL, Stuart. Cultural identity and diaspora. In: RUTHERFORD, J. Identity: community, culture and difference. Londres, Lawrence \& Wishart, 1990.

. Da diáspora: identidades e mediações culturais. Belo Horizonte, Editora UFMG, 2013.

HARAWAY, Donna. Saberes localizados: a questão da ciência para o feminismo e o privilégio da perspectiva parcial. cadernos pagu (5) 1995, pp.07-41.

hooks, bell. Olhares negros: raça e representação. São Paulo, Elefante, 2019.

MBEMBE, Achille. Crítica da razão negra. Lisboa, Antígona, 2014.

NASCIMENTO, Abdias. O quilombismo: Documentos de uma militância Pan-Africanista. Rio de Janeiro e São Paulo, IPEAFRO e Perspectiva, 2019.

NASCIMENTO, Beatriz. Beatriz Nascimento, Quilombola e Intelectual: Possibilidade nos dias da destruição. Diáspora Africana, Editora Filhos da África, 2018.

RASCAROLI, Laura. The essay film: problems, definitions, textual commitments. Framework: The Journal of Cinema and Media, vol. 49, n. 02 , outono 2008, pp.24-47

RATTS, Alex. Eu sou Atlântica. Sobre a trajetória de vida de Beatriz Nascimento. São Paulo, Imprensa Oficial, 2006. 